www.jmscr.igmpublication.org

Impact Factor 3.79

Index Copernicus Value: 5.88 ISSN (e)-2347-176x ISSN (p) 2455-0450 crossref DOI:_http://dx.doi.org/10.18535/jmscr/v3i11.14

\title{
Clinical Utility of Alfa- Fetoprotein-L3 in Hepatocellular Carcinoma Patients
}

\author{
Authors \\ Ayman Mohamed Shamseya ${ }^{1}$, Wafaa Mohamed Hussein Elsheikh ${ }^{2}$, Mohamed Mohamed \\ Shamseya ${ }^{3}$, Amal El Mahdi Mohamed Shafaey ${ }^{4}$, Khaled Mustapha Belal ${ }^{5} \&$ \\ Waleed Said Mohamed Moftah \\ ${ }^{1,2}$ Dept of Internal Medicine, Faculty of Medicine, University of Alexandria \\ ${ }^{3}$ Dept of Clinical and Experimental Internal Medicine; Medical Research Institute, University of Alexandria \\ ${ }^{4,5,6}$ Dept of Clinical and Chemical Pathology, Faculty of Medicine, Benha University \\ Email: 1dr.ayman1977@gmail.com, ${ }^{2}$ wfaaelshikh@yahoo.com, ${ }^{3}$ mohamed.shamseya@yahoo.com, \\ ${ }^{4}$ A.elmahdy@fmed.bu.edu.eg, ${ }^{5}$ Khaledbelal1960@yahoo.com, ${ }^{5}$ First_fowalab@yahoo.com \\ Corresponding Author \\ Dr Ayman Mohamed Abdou Shamseya
}

Lecturer, Department of Internal Medicine, Faculty of Medicine, University of Alexandria, Egypt

Address: 21, Elsayed Radwan St, Miami, Alexandria, Egypt

Email:dr.ayman1977@gmail.com, Phone: +201222903176

\begin{abstract}
Patients at risk for HCC should undergo surveillance with ultrasonography, CT scan, or MRI at 6-monthly intervals. Serum- $\alpha$-fetoprotein (AFP) and protein induced vitamin $K$ absence (PIVKA)-II are the most common markers available to detect HCC. Des gamma carboxyprothrombin (DCP), AFP-L3 (a glycosylated form of AFP which is produced in higher concentration by HCC than normal liver), Golgi membrane protein 73 (GP73), and glypican 3 (GPC3) have been proposed as surveillance tests for HCC. In patients with small tumors or in well-tomoderately differentiated HCC, serum markers rarely elevated. Therefore, there is a need for the development of more sensitive and specific methods that supplement these tumor markers for the early detection of HCC. The present study included 46 patients with HCC, 20 patients with benign hepatic disorders and 20 sex-and agematched apparent healthy individuals as a control group. The median value of both serum AFP-L3 and AFPL3/AFP ratio was significantly higher in HCC patients group compared to other groups. There was a significant positive correlation between each of serum AFP, AFP-L3, with each of child classification, tumor size and tumor number, among HCC patients. The best cut-off point for AFP as predictor of HCC was $62 \mathrm{ng} / \mathrm{mL}$, for AFP-L3 as predictor of $H C C$ was $15 \mathrm{ng} / \mathrm{mL}$ and for AFP-L3/AFP ratio was $20 \%$. Combination of AFP and AFP-L3 revealed best cut-off of $A F P$ at $100 \mathrm{ng} / \mathrm{mL}$ and $A F P-L 3$ at $4 \mathrm{ng} / \mathrm{mL}$. In conclusion AFP-L3 is a promising marker for diagnosis of HCC especially when combined with AFP.
\end{abstract}

Keywords: Alfa-Fetoprotein, Hepatocellular Carcinoma, tumor markers. 


\section{INTRODUCTION}

Diagnosis of HCC depends on clinical evaluation, laboratory diagnosis, imaging techniques and histopathological techniques. The patient may be completely asymptomatic with no physical signs other than those of cirrhosis. Therefore the laboratory markers of HCC are very important in early diagnosis for better $\operatorname{prognosis}^{(1)}$.

Patients at risk for HCC should undergo surveillance with ultrasonography, CT scan, or MRI at 6-monthly intervals. Serum- $\alpha$-fetoprotein (AFP) and protein induced vitamin K absence (PIVKA)-II are the most common markers available to detect HCC. AFP has low specificity and unsatisfactory sensitivity in the diagnosis of early HCC. Thus, there is need for supplementary markers for AFP to increase the sensitivity in early diagnosis of HCC as well as the specificity in differentiation between HCC and benign lesions ${ }^{(2,3)}$.

Total AFP can be divided into three different glycoforms, namely AFP-L1, AFP-L2 and AFP-L3, according to their binding capability to lectin lens culinaris agglutin. Some clinical researches have indicated that the high percentage of AFP-L3 is closely related to poor differentiation and biologically malignant characteristics, especially portal vein invasion as it is produced only from malignant liver cells of $\mathrm{HCC}^{(4)}$.

Over the past decades, researches have shown that total AFP is a collection of heterogeneous glycoproteins consisting of three different glycoforms. AFP from benign chronic liver diseases, such as chronic hepatitis and liver cirrhosis, and from HCC displayed differential affinities to a lectin, the lens culinaris agglutinin (LCA). The total AFP can be separated into three subspecies, AFP-L1 to AFP-L3, based on its reactivity to LCA on affinity electrophoresis. AFP-L3 has LCA-binding activity. It appears to be produced only by cancer cells. Clinical research has suggested AFP-L3 as a marker of $\mathrm{HCC}^{(5)}$.

The aim of this study was to assess the diagnostic value of AFP-L3 in HCC patients and its role in prognosis through its relation to different HCC stages. The results of AFP- L3 were compared to the routinely done AFP in order to explore whether it is superior or not in the diagnosis and prognosis of HCC patients.

\section{SUBJECTS AND METHODS}

SUBJECTS: eighty six (86) subjects whose were classified into three groups:

\section{Group 1: Hepatocellular Carcinoma Patients $(n=46)$}

Diagnosis of HCC was confirmed by spiral CT. They were 40 males and 6 females, whose ages ranged from 41 to 58 years (mean $49.1 \pm 4.4$ ). According to (BCLC) staging system, they were divided into:

Stage A subgroup $(\mathrm{n}=20)$ : Single tumor $<5 \mathrm{~cm}$. This included 16 males and 4 females, with a mean age of $49.8 \pm 4.6$.

Stage B subgroup $(n=17)$ : Large multinodular tumor, Child-Pugh A-B. This included 15 males and 2 females, with a mean age of $48 \pm 4.5$.

Stage C subgroup ( $n=9)$ : In which there is vascular invasion, extrahepatic manifestations, Child-Pugh A-B.

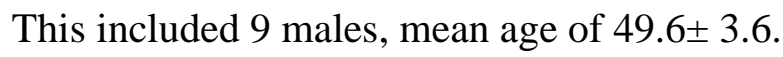

\section{2) Group 2: Pathological Control Patients $(\mathbf{n}=20)$}

This included 20 patients with benign hepatic disorders such as chronic hepatitis and liver cirrhosis. The diagnosis was based on the clinical picture, ultrasonography, elevated AST, low albumin and prolonged prothrombin time (PT). They were 18 males and 2 females, whose age ranged from 42 to 56 years (mean 48.5 $\pm 4.2)$. 


\section{3) Group 3: Healthy Control $(\mathbf{n}=20)$}

This included 20, sex and age matched healthy individuals. They were 17 males and 3 females, whose age ranged from 41 to 58 years (mean $49.1 \pm 4.3$ ).

\section{Sampling:}

Freshly drawn $6 \mathrm{~mL}$ blood was divided to $1.8 \mathrm{ml}$, collected on citrated tube for prothrombin time, and the rest was collected on sterile vaccutainer. Serum was separated by centrifugation at $1000 \mathrm{xg}$ for 10 minutes. One milliliter serum was used for immediate assay of AST, ALT, albumin, total bilirubin. The rest was stored at freezer or at $-20^{\circ} \mathrm{C}$ till assay of AFP and AFP- L3.

\section{RESULTS}

Table (1): Statistical comparison of laboratory parameters in the different studied groups using Mann Whitney U test

\begin{tabular}{|c|c|c|c|c|}
\hline \multicolumn{2}{|l|}{ Parameter } & $\begin{array}{l}\text { Group I vs. } \\
\text { Group II }\end{array}$ & $\begin{array}{l}\text { Group I } \\
\text { Group III }\end{array}$ & $\begin{array}{l}\text { Group II vs. } \\
\text { Group III }\end{array}$ \\
\hline \multirow{2}{*}{ I.N.R } & $\mathbf{Z}$ & +4.35 & +5.93 & +0.95 \\
\hline & $\mathrm{P}$ & $<0.01$ & $<0.01$ & $>0.05$ \\
\hline \multirow{2}{*}{ ALT } & $\mathbf{Z}$ & +2.77 & +6.42 & +5.42 \\
\hline & $\mathrm{P}$ & $<0.01$ & $<0.01$ & $<0.01$ \\
\hline \multirow{2}{*}{ AST } & $\mathbf{Z}$ & +2.63 & +6.41 & +5.42 \\
\hline & $\mathrm{P}$ & $<0.01$ & $<0.01$ & $<0.01$ \\
\hline \multirow[t]{2}{*}{ Albumin } & $\mathbf{t}$ & -2.43 & -4.96 & -1.81 \\
\hline & $\bar{P}$ & $<0.05$ & $<0.01$ & $>0.05$ \\
\hline \multirow[t]{2}{*}{ T. Bilirubin } & $\mathbf{Z}$ & -3.81 & -5.04 & -1.83 \\
\hline & $\mathrm{P}$ & $<0.01$ & $<0.01$ & $>0.05$ \\
\hline \multirow{2}{*}{ AFP } & $\mathbf{Z}$ & +4.53 & +6.43 & +5.39 \\
\hline & $\mathrm{P}$ & $<0.01$ & $<0.01$ & $<0.01$ \\
\hline \multirow{2}{*}{ AFP-L3 } & $\mathbf{Z}$ & +5.36 & +6.47 & +2.86 \\
\hline & $\bar{P}$ & $<0.01$ & $<0.01$ & $<0.05$ \\
\hline \multirow{2}{*}{$\begin{array}{l}\text { AFP-L3/AFP } \\
\text { ratio }\end{array}$} & $\mathbf{Z}$ & +4.15 & +6.17 & +2.80 \\
\hline & $\mathrm{P}$ & $<0.01$ & $<0.01$ & $<0.05$ \\
\hline
\end{tabular}

This revealed that median serum levels of AFP-L3 showed a highly significant difference in group I when compared to group II $(\mathrm{p}<0.01)$ and when compared to group III $(\mathrm{p}<0.01)$, and significant difference in group II when compared to group III $(\mathrm{p}<0.05)$

Concerning the median value of AFP-L3/AFP ratio, it gave significantly higher results in cases of group I when compared to cases of group II and group III $(\mathrm{p}<0.01)$, significant difference when compared between group II and III $(\mathrm{P}<0.05)$ 
Table (2): Statistical comparison of AFP (ng/mL), AFP-L3 (ng/mL), AFP-L3/AFP ratio among the 3 different stages of the HCC cases using Kruskall Wallis test

\begin{tabular}{|c|c|c|c|c|c|}
\hline Parameter & $\begin{array}{l}\text { Stage A } \\
(\mathbf{n}=20) \\
\text { Median (IQR) }\end{array}$ & $\begin{array}{l}\text { Stage B } \\
(\mathbf{n}=17) \\
\text { Median (IQR) }\end{array}$ & $\begin{array}{l}\text { Stage C } \\
(\mathbf{n}=9) \\
\text { Median (IQR) }\end{array}$ & $\boldsymbol{H}$ & $P$ \\
\hline AFP (ng/mL) & $\begin{array}{lll}85 & (82.5 & - \\
159.8) & \end{array}$ & $110(90-619)$ & $367(150-784)$ & $\begin{array}{l}7.3 \\
1\end{array}$ & $<0.05$ \\
\hline AFP-L3 (ng/mL) & $35(20-97.5)$ & $\begin{array}{lll}50 \quad(15 & - \\
112.5) & \end{array}$ & $130(111-136)$ & $\begin{array}{l}12 . \\
0\end{array}$ & $<0.01$ \\
\hline AFP-L3/AFP ratio & $\begin{array}{lll}0.33 & (0.23 & - \\
0.56) & & \\
\end{array}$ & $\begin{array}{lll}0.22 & (0.1 & - \\
0.53) & & \\
\end{array}$ & $\begin{array}{lll}0.37 & (0.14 & - \\
0.86) & & \\
\end{array}$ & 2.2 & $>0.05$ \\
\hline
\end{tabular}

As regard the prognostic role of AFP and AFP-L3, the median values of them were significantly increasing from stage A to $\mathrm{C}$

Table (3): Comparisons of AFP, AFP-L3 and AFP-L3/AFP among the 3 stages of HCC cases using Mann Whitney U test

\begin{tabular}{||l|l|c|c|c|}
\hline \multirow{2}{*}{ Parameter } & $\begin{array}{c}\text { Stage } \\
\text { A vs. B }\end{array}$ & $\begin{array}{c}\text { Stage } \\
\text { A vs. C }\end{array}$ & $\begin{array}{c}\text { Stage } \\
\text { B vs. C }\end{array}$ \\
\hline \multirow{2}{*}{ AFP } & $\mathrm{Z}$ & -1.6 & -2.45 & -1.5 \\
\cline { 2 - 5 } & $\mathrm{P}$ & $>0.05$ & $>0.05$ & $>0.05$ \\
\hline \multirow{2}{*}{ AFP-L3 } & $\mathrm{Z}$ & -0.6 & -3.47 & -2.64 \\
\cline { 2 - 5 } & $\mathrm{P}$ & $>0.05$ & $>0.01$ & $>0.01$ \\
\hline \multirow{2}{*}{ AFP-L3/AFP } & $\mathrm{Z}$ & +0.8 & -0.87 & -1.43 \\
\cline { 2 - 5 } & $\mathrm{P}$ & $>0.05$ & $>0.05$ & $>0.05$ \\
\hline \hline
\end{tabular}

Table (4): Correlation between Serum AFP, AFP-L3, AFP-L3/AFP ratio other parameters Among Patients of Group I (HCC Group)

\begin{tabular}{|l|l|l|l|l|}
\hline \multicolumn{2}{|c|}{} & AFP & AFPL3 & Ratio \\
\hline \multirow{3}{*}{ Child score } & $\boldsymbol{R}$ & 0.23 & 0.36 & 0.15 \\
\cline { 2 - 5 } & $\boldsymbol{P}$ & $<0.05$ & $<0.05$ & $>0.05$ \\
\hline \multirow{3}{*}{ Tumor No. } & $\boldsymbol{R}$ & 0.21 & 0.23 & 0.04 \\
\cline { 2 - 5 } & $\boldsymbol{P}$ & $<0.05$ & $<0.05$ & $>0.05$ \\
\hline \multirow{2}{*}{ Age (years): } & $\boldsymbol{R}$ & 0.19 & 0.20 & -0.14 \\
\cline { 2 - 5 } & $\boldsymbol{P}$ & $<0.05$ & $<0.05$ & $>0.05$ \\
\hline \multirow{2}{*}{ AFP (ng/ml): (cut off 62) } & $\boldsymbol{R}$ & -0.21 & -0.09 & 0.22 \\
\cline { 2 - 5 } & $\boldsymbol{P}$ & $>0.05$ & $>0.05$ & $>0.05$ \\
\hline \multirow{2}{*}{ ALT (IU/L): (cut off 67) } & $\boldsymbol{R}$ & - & 0.8 & -0.37 \\
\cline { 2 - 5 } & $\boldsymbol{P}$ & - & $<0.01$ & $<0.05$ \\
\hline \multirow{2}{*}{ Albumin (g/ml): (cut off 3) } & $\boldsymbol{R}$ & -0.03 & 0.26 & 0.33 \\
\cline { 2 - 5 } & $\boldsymbol{P}$ & $>0.05$ & $>0.05$ & $<0.05$ \\
\hline \multirow{2}{*}{ Bilirubin (mg/dl): (cut off 2.9) } & $\boldsymbol{R}$ & -0.29 & -0.16 & 0.21 \\
\cline { 2 - 5 } & $\boldsymbol{P}$ & $>0.05$ & $>0.05$ & $>0.05$ \\
\hline \multirow{2}{*}{ INR (cut off 1.6) } & $\boldsymbol{R}$ & 0.12 & 0.26 & 0.12 \\
\cline { 2 - 5 } & $\boldsymbol{P}$ & $>0.05$ & $>0.05$ & $>0.05$ \\
\cline { 2 - 5 } & $\boldsymbol{P}$ & -0.06 & -0.05 & 0.06 \\
\hline
\end{tabular}

There was a significant correlation between each of serum AFP, AFP-L3 and each of child classification, tumor size and tumor number, among patients of group I 
There was a non-significant correlation between age and each of serum AFP, AFP-L3 and AFP-L3/AFP ratio among group I. There was a significant correlation between AFP and AFP-L3/AFP ratio.

Table (5): Performance characteristics of AFP, AFP-L3and AFP-L3/AFP ratio in the present study as regard group I versus II at cut-off 95 th percentile specificity.

\begin{tabular}{|l|c|c|c|c|c|c|}
\hline & Cut-off & SP\% & SN\% & NPV\% & PPV\% & Efficacy\% \\
\hline AFP & $110 \mathrm{ng} / \mathrm{Ml}$ & 95 & 50 & 45 & 96 & 64 \\
\hline AFP-L3 & $27 \mathrm{ng} / \mathrm{mL}$ & 95 & 70 & 58 & 97 & 76 \\
\hline AFP-L3/AFP ratio & $24 \%$ & 95 & 61 & 52 & 97 & 71 \\
\hline
\end{tabular}

By testing the performance at a cut-off of $95^{\text {th }}$ percentile specificity, it was found that AFP-L3 had the best performance, sensitivity of $70 \%$, NPV 52\%, PPV $97 \%$ and efficacy of $76 \%$.

Table (6): ROC and multi ROC analysis of AFP, AFP-L3and AFP-L3/AFP ratio in the present study as regard group I versus II

\begin{tabular}{|c|c|c|c|c|c|c|}
\hline & Cut-off & Z & $\frac{5}{9}$ & $\frac{3}{3}$ & $\frac{7}{2}$ & 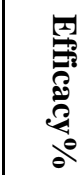 \\
\hline AFP & $62 \mathrm{ng} / \mathrm{mL}$ (Best cut-off) & 83 & 80 & 67 & 91 & 82 \\
\hline AFP-L3 & $15 \mathrm{ng} / \mathrm{mL}$ (Best cut-off) & 83 & 85 & 68 & 93 & 83 \\
\hline $\begin{array}{l}\text { AFP-L3/AFP } \\
\text { ratio }\end{array}$ & $20 \%$ (Best cut-off) & 70 & 75 & 52 & 87 & 71 \\
\hline $\begin{array}{l}\text { Combination of } \\
\text { AFP } \\
\text { And AFP-L3 } \\
\text { AFP-L3 }\end{array}$ & $\begin{array}{l}100 \mathrm{ng} / \mathrm{mL} \text { for AFP and } 4 \\
\mathrm{ng} / \mathrm{mL} \text { for AFP-L3 }\end{array}$ & 100 & 85 & 100 & 94 & 96 \\
\hline
\end{tabular}

The best cut-off point for AFP as predictor of HCC was $62 \mathrm{ng} / \mathrm{mL}$ (sensitivity $83 \%$, specificity $80 \%$, PPV $91 \%$, NPV $67 \%$ and efficacy $82 \%$ ).

The best cut off point for AFP-L3 as predictor of HCC was $15 \mathrm{ng} / \mathrm{mL}$ (sensitivity $83 \%$ specificity $85 \%$, PPV 93\%, NPV 68\% and efficacy $83 \%$ ).

The best cut-off point for AFP-L3/AFP ratio was $20 \%$ (sensitivity 70\%, specificity 75\%, PPV $87 \%$, NPV $52 \%$ and efficacy $71 \%$ ).

Combination of AFP and AFP-L3(subjects considered having HCC when being positive for both AFP and-or AFP-L3)revealed best cut-off of AFP at $100 \mathrm{ng} / \mathrm{mL}$ and AFP-L3 at $4 \mathrm{ng} / \mathrm{mL}$ giving sensitivity of $100 \%$,specificity of $85 \%$,PPV $94 \%$,NPV $100 \%$ and efficacy $96 \%$.

Receiver operator characteristics (ROC) curves were constructed for serum AFP, AFP-L3 and AFP-L3/AFP ratio as predictors of HCC. Serum AFP-L3 had the largest area under the curve (AUC) when compared to serum AFP and AFP-L3/AFP ratio. 


\section{DISCUSSION}

In the present study, it was found that the median value of both serum AFP-L3 and AFP-L3/AFP ratio are significantly higher in HCC patients group when compared to chronic liver disease patients and normal control individuals, that is matching with the study by Davi et al.(2001) revealing that AFP-L3 is produced only from malignant liver cells ${ }^{(6)}$.

In another study, Li et al. (2001) studied the presence of AFP-L3 in chronic liver disease patients suspected to have HCC. They found that 57\% of AFP-L3 positive cases were diagnosed as HCC in the following 6 months and 6 of them were diagnosed to be single small HCC at the early stage through ultrasonic diagnosis or CT ${ }^{(5)}$. The median value for serum AFP- L3 and the ratio was increasing from stage A to stage C and was higher in stage C. This is matching with the data from Davi et al. (2001) who stated that AFP-L3 increases with advanced tumor stages and that the liver cancer cells with expression of AFP- L3 have tendency toward early vascular invasion and a potential for rapid growth, so it may be used as prognostic tool ${ }^{(6)}$.

Also in study by Oka et al. (2001), who studied 388 patients of HCC during a year. They found that AFP-L3 positive patients were having advanced tumor characteristics in the form of maximum diameter, portal vein invasion and tumor stage ${ }^{(7)}$.

Another study, Tada et al. (2005) studied the biological behavior of HCC positive for AFP-L3 in a total of 111 HCC patients who underwent hepatic resection. Pathologic features of resected HCC specimens were evaluated and classified concerning growth pattern (expansive or infiltrative growth), capsule formation, capsule infiltration, septal formation, portal vein invasion, hepatic vein invasion, bile duct invasion, and intrahepatic metastasis. They found that those features were significantly higher in AFP-L3 positive tumors compared to AFP-L3 negative tumors ${ }^{(8)}$.

This result was confirmed by Yamashita et al. (1996) who assessed serum AFP-L3 in 55 patients of HCC who underwent different methods of treatment. They found that $50 \%$ converted to positive and by further investigations these patients were found to have HCC recurrence and portal vein invasion ${ }^{(9)}$.

This is also supported by the data collected by Song et al. (2002) who studied the serum AFP-L3 as pretreatment assessment. They found that those patients who were positive for AFP-L3 had a very poor response to therapy ${ }^{(10)}$.

Kumada et al. (1999) stated that AFP-L3/AFP ratio of $10 \%$ in patients having liver cirrhosis is associated with 7 fold increased risk for developing HCC in the next 21 months and could be detected 3 to 21 months prior to standard imaging techniques ${ }^{(11)}$.

A study done by Kazohisha et al. (1993) who studied the sera of 422 patients stated that AFP-L3/AFP ratio with a cut-off value of $15 \%$ could predict the occurrence of HCC in cirrhotic liver four months before the imaging techniques ${ }^{(12)}$.

Serum AFP was significantly higher in HCC patients than in patients with benign liver diseases and control subjects. Assessment of the diagnostic performance of AFP as a marker for distinguishing HCC from benign liver diseases and healthy candidates revealed that at a cut-off $20 \mathrm{ng} / \mathrm{mL}$ (manufacturer cut-off) the diagnostic sensitivity was $100 \%$, the specificity was $40 \%$, PPV was $79 \%$, NPV was $100 \%$ and efficacy was $82 \%$.

AFP -L3 showed sensitivity of 83\%, specificity 85\%, PPV 93\% and NPV 68\%, therefore, more specific than AFP. That is close to study by Evi et al. (2008) in which AFP- L3 showed sensitivity of 90\% and 95\% specificity. A possible cause for their higher performance is that they studied larger number of cases $(n=334)$ which included larger tumor sizes ${ }^{(13)}$. 
In a study by Davi et al. (2001) who assessed the diagnostic performance of AFP-L3 in the diagnosis of HCC, the sensitivity of AFP-L3 was found to be stage-related in HCC. The overall sensitivity of AFP-L3 for HCC was approximately $60 \%$. In small HCC (HCC $<2 \mathrm{~cm}$ in diameter) AFP-L3 had a sensitivity of only $45 \%$. The sensitivity increased with increase in size of the HCC, and reached $90 \%$ when $\mathrm{HCC}$ was $5 \mathrm{~cm}$ in diameter or greater $^{(6)}$.

Shiraki et al. (1996) examined the diagnostic performance of AFP-L3 in HCC patients.AFP-L3 had a sensitivity of $75 \%$ and specificity of $90 \%$ but he used larger number of HCC patients $(n=2000){ }^{(14)}$.

AFP- L3/AFP ratio with $20 \%$ as a cut-off value had a sensitivity of $70 \%$, specificity of $75 \%$, PPV of $87 \%$ and NPV of 52\%.This was close to the study by Tanwandee et al. (2009) who had a cut-off $15 \%$ yielding a sensitivity of $82 \%$ specificity of $71 \%$, PPV of $83 \%$ and NPV of $69 \%$ but he used different staging system and had larger number of HCC patients $(n=61)^{(15)}$.

Apinya et al. (2007) studied 166 cases of HCC and 106 cases of benign liver conditions. When a cut-off value of $10 \%$ was used, it gave a sensitivity of $71 \%$ and specificity of $63 \%$ and by using a cut-off value of $35 \%$, it gave a sensitivity of $33 \%$ and specificity of $100 \%{ }^{(16)}$.

A study by Sangiovanni et al. (2010) assessed the diagnostic performance of AFP-L3/AFP ratio in 86 HCC patients and 38 patients with other liver conditions. By a cut-off value of $7 \%$, it gave a sensitivity of $60 \%$ and specificity of $80 \%$. A possible cause for the discrepancy in the cut-offs in the above studies is the target of each study in choosing the more specific or more sensitive marker according to the need of different countries (17)

When the diagnostic performance of AFP and AFP-L3 was tested in combination in table (6), they had a sensitivity of $100 \%$ and specificity of $85 \%$, so there is improvement in sensitivity. That is contradictory to data by Leerapun et al. (2007) who stated that determination of AFP-L3, in combination with AFP, increases the specificity of diagnosis of HCC in individuals with HCC but he studied large number of HCC patients $(\mathrm{n}=272)^{(18)}$.

The increasing incidence of HCC, in addition to the fact that the majority of these tumors are diagnosed at a late stage when curative treatments are not possible, implicate that performing regular surveillance of high risk individuals is recommended.

Financial support / grants: The authors declare no financial support / grants regarding this work.

Conflict of interest: The authors declare no conflict of interest regarding this work.

\section{REFERENCES}

1. Filmus J. and Capurro M. (2004): Glypican-3 and alphafetoprotein as diagnostic tests for hepatocellular carcinoma. Mol. Diagn.; 8: 207.

2. Wei J.J.; Xiao B.M.; Liang T.; Hong Y.S.; Shen J.L.; Guo J.C.; Xiu H.Q. and He PH. (2006): Shanghai China Hepatobiliary Pancr. Dis. Int.; 5:257.

3. Hong, Y.H.J., Li, H., Chen, S., Liu, Q., Zhang, B., He, X., Wang, Y., Li, H., Li, Y., Zhang, T., Lu, C., Yan, H., Zhang, M., Li, Q., Cao, B., Bai, Z., Wang, J., Zhang, Z., Zhu, S., Zhen, J., Ou, X., Ma, H., JIa, J., You, H., Wang, S., and Huang, J. An analysis of immunoreactive signatures in early stage hepatocellular carcinoma. EBioMedicine. 2015; 2: 438-446

4. Lin Z.; Liu J. and Luo F. (2006): Serum tumor markers for detection of hepatocellular carcinoma.World J. Gastroenterol.; 12: 1175. 
5. Li D.; Mallory T. and Satamura S. (2001): AFP-L3 a new generation of tumor marker for hepatocellular carcinoma.Clinica Chemica Acta; 313:15-19.

6. Davi ET.; Du MQ.; Hutchinson WL.; Johnson PJ.; and Williams R. (2001): Differential alphafetoproteinlectin binding in hepatocellular carcinoma. Diagnostic utility at low serum levels. Cancer; 67:476-80.

7. Oka H.; Saito A and Ito K.(2001): Multicenter prospective analysis of newly diagnosed hepatocellular carcinoma with respect to the percentage of Lens culinaris agglutinin-reactive $\alpha$-fetoprotein.J Gastroen Hepato.;16:1378-1383.

8. Tada T.; Kumada T and Toyoda. (2005): Relationship between Lens culinaris agglutinin-reactive $\alpha$ fetoprotein and pathological features of hepatocellular carcinoma. Liver Int.; 25:848-853

9. Yamashita F.; Tanaka M.; Satomura S and Tanikawa K. (1996): Prognostic significance of Lens culinaris agglutinin A-reactive alpha-fetoprotein in small hepatocellular carcinomas. Gastroenterology; 111:996-1001.

10. Song B.C.; Chung Y.H.; Kim J.A.; Choi W.B.; Suh D.D.; Pyo S.I.; Shin J.W.; Lee H.C.; Lee Y.S. and Suh D.J. (2002): Transforming growth factor-betal as a useful serologic marker of small hepatocellular carcinoma. Cancer; 94:175.

11. Kumada T.; Nakano S and Takeda I. (1999): Clinical utility of Lens culinaris agglutinin-reactive alpha-fetoprotein in small hepatocellular carcinoma. Special reference to imaging diagnosis. J. Hepatol.; 30:125-130.

12. Motawa E.; Mohammed S.; Wael M.; Tarek D.; Omar S. and Anwar A. (2006): Enhanced Detection of Hepatocellular Carcinoma. Cancer Control; 12:248-253.

13. Evi N. Debruyne and Joris R. Delanghe (2008): Diagnosing and monitoring hepatocellular carcinoma with alpha-fetoprotein,new aspects and applications, Clinica. Chimica. Acta. ; 359: 19-26.

14. Shiraki K.; Takase K.; Tameda Y.; Hamada M.; Kosaka Y and Nakano T. (1996): clinical study of lectin-reactive alpha-fetoprotein as an early indicator of hepatocellular carcinoma in the follow-up of cirrhotic patients. Hepatology; 22:802-7.

15. Tanwandee T.; Setthasin S.; Charatcharoenwitthaya P.; Chainuvati S.; Leelakusolvong S.; Pausawasdi N.; Srikureja W.; Pongprasobchai S.; Manatsathit S.; Kachintorn U.; Ekpo P and Senawong S. (2009): Clinical utility of lens culinaris agglutinin-reactive alpha-fetoprotein in the diagnosis of hepatocellular carcinoma: evaluation in a Thai referral population. J Med Assoc Thai.; 92: 49-56.

16. Apinya Leerapun.;Sri V.; Suravarapu John P.;BidaRaynell J.; Elizabeth L.; Sanders Teresa A.; Mettler Linda M.; Ileana Aderca.; Catherine D.; Moser, David M.; Nagorney.; Nicholas F.; LaRusso.; Piet C.; Narayanan Menon.; Konstantinos N.; and Lewis R. Roberts (2007): The utility of AFP-L3in the diagnosis of HCC. Clin. Gastroenterol. Hepatol. ; 5: 394-267.

17. Sangiovanni A.; Romeo R.; Iavarone M.; Vavassori S.; Della C.; and Colombo M. (2010): Diagnostic value of lens AFP-L3 and DCP for the diagnosis of HCC. Journal of Hepatology ; 52 : 183-317

18. Leerapun A.; Louis L.; Tamara S.; David C.; Sara V.B.; Jacques P.; Frederik N.; Chris V.; Jos V. P. and Tania R. (2006): Glypican-3 Expression Distinguishes Small hepatocellular carcinomas from cirrhosis, dysplastic nodules, and focal nodular hyperplasia-like nodules. The Am. J. Surg. Path.; 30:11. 